\title{
XÁC ĐỊNH KHẢ NĂNG XẢY RA ĐẶC TRƯNG CỰC TR! CƯỜNG ĐỘ BÃO VÀ NƯỚC DÂNG DO BÃO ĐẾN CÁC KHU VỰC VEN BIÊNN DỰA TRÊN CÁC MÔ PHỎNG KHÍ TƯợNG - HẢI VĂN
}

\author{
Trần Hồng Thái ${ }^{1}$, Mai Văn Khiêm ${ }^{1}$, Nguyễn Văn Hưởng ${ }^{1}$, Nguyễn Bá Thủy ${ }^{1}$, Dư Đức Tiến ${ }^{1}$
}

Tóm tắt: Bão Haiyan năm 2013 là conn bão mạnh nhất trong lịch sủ khi đổ bộ vào đất liền. Thiệt hại do bão Haiyan gây ra đối với Philippin là hết sức nặng nề về người và tài sản. Nhằm tránh nhũng thiệt hại tuoong tụ đối với Việt Nam, Thủ twớng Chính phủ đã yêu cầu chuẩn bị các phuơng án ứng phó với siêu bão, và đặc biệt là các co sở khoa hoc để đưa ra được các nhận định so bộ về khả năng xảy ra đặc trung cực trị cuờng độ bão và nước dâng do bão đến các khu vưc ven biển của Việt Nam (Công văn số 3912/VPCP-KTN ngày 30 tháng 5 năm 2014 của Văn phòng Chính phủ về việc triển khai các nhiệm vụ nhằm chủ động phòng ngùa ứng phó với tình huống siêu bão). Việc sủ dụng các mô phỏng vật lý và đặc biệt là phưong pháp tổ hợp tù các mô hình khí tương và mô hình hải văn sẽ cho phép cung cấp được các thông tin về các khả năng xảy ra các hiện tượng cực trị về cuờng độ bão và nước dâng do bão bên cạnh các thông tin về tính cưc trị đã xảy ra tù các số liệu quan trắc trong quá khứ trên khu vục ven biển Việt Nam.

Từ khóa: Nước dâng do bão, cuờng độ bão mạn, ven biển Việt Nam.

Ban Biên tập nhận bài: 11/12/2019 Ngày phản biện xong: 12/12/2019 Ngày đăng bài: 20/12/2019

\section{Mở đầu}

Một trong những hạn chế chính của việc sử dụng các quan trắc trong quá khứ để đánh giá những giá trị mang tính cực trị do bão cho một khu vực nhất định là không có được những thông tin có thể xảy ra trong quá khứ mà tập quan trắc có thể bao phủ được. Để khắc phục được vấn đề này, các hệ thống mô phỏng bằng mô hình động lực được sử dụng, trong đó các quá trình phi tuyến được mô tả đầy đủ sẽ cho phép phát hiện/cung cấp được các thông tin có thể xảy ra mà tập quan trắc trong quá khứ không thể mô tả. Ngoài ra, từ những năm 70 lý thuyết dự báo tổ hợp được đặt nền móng và bắt đầu đưa vào ứng dụng đầu những năm 90 của thế kỷ trước với mục đích chính cho đến nay là ứng dụng cho các dự báo hạn vừa trên các quy mô hiện tượng khác nhau, từ quy mô hành tinh đến quy mô vừa và quy mô dưới vừa. Cho đến nay, dự báo tổ hợp
(Ensemble Forecast) đã được ứng dụng để dự báo hạn ngắn với các quá trình quy mô vừa cùng sự xuất hiện của rất nhiều phương pháp hiệu chỉnh dự báo tổ hợp. Thừa nhận độ bất định (uncertainty) trong dự báo, dự báo tổ hợp không chỉ dự báo các yếu tố khí tượng-hải văn thông thường mà còn đưa ra độ bất định ứng với mỗi yếu tố dự báo. Quan trọng hơn, dự báo tổ hợp còn cho phép thực hiện dự báo xác suất, loại hình dự báo cần được thực hiện tại các trung tâm dự báo, rất khác so với dự báo tất định (deterministic forecast) truyền thống.

Có hai lớp thông tin mô phỏng để cung cấp các đặc tính cực trị bao gồm: i) từ các "dự tính" từ các mô hình Trái Đất (Earth simulation models), trong đó các mô hình toàn cầu được tích phân ở một thời gian dài (có thể đến 100 năm) với các kịch bản biến đổi khí hậu khác nhau; và ii) các hệ thống mô phỏng tổ hợp trong đó ứng 
với một điều kiện khí quyển đại dương nhất định (mô phỏng tất định), những nhiễu động xung quanh điều kiện nhất định này hoặc tính bất định trong chính mô phỏng khí quyển-đại dương sẽ cho phép có được các mô phỏng thành phần với các thông tin cực trị bên cạnh các mô phỏng tất định.

Nghiên cứu này sẽ trình bày hai lớp thông tin như đã nêu cho việc xác định các khả năng xảy ra các hiện tượng cực trị về cường độ bão và nước dâng do bão bên cạnh các thông tin về tính cực trị đã xảy ra từ các số liệu quan trắc trong quá khứ trên khu vực ven biển Việt Nam bao gồm: i) từ hệ thống mô phỏng động lực khí quyển và từ ii) mô phỏng động lực - thống kê hải văn. Đối với thông tin mô phỏng động lực khí quyển sẽ bao gồm hệ thống mô phỏng tổ hợp ở các quy mô từ toàn cầu đến khu vực và cả thông tin từ các hệ thống dự tính khí hậu chi tiết. Đối với thông tin mô phỏng động lực-thống kê hải văn, ngoài việc sử dụng các mô phỏng từ các mô hình hải văn để tính nước dâng do bão, Một trong những tiếp cận để đánh giá nguy cơ bão cũng như nước dâng và sóng lớn trong bão mà nghiên cứu lựa chọn là sử dụng phương pháp Monte - Carlo để xây dựng tập hợp bão phát sinh thống kê trong 1000 năm qua đó nguy cơ về cấp bão có thể xuất hiện tại từng khu vực và hệ quả nước biển dâng do bão và sóng lớn trong bão sẽ được tính toán và phân tích chi tiết cho từng khu vực. Các thông tin về phương pháp và số liệu được trình bày trong phần 2 của bài báo trong khi các kết quả và kết luận chung được trình bày lần lượt trong phần 3 và phần 4 .

2 Các phương pháp mô phỏng bão mạnh và siêu bão phát sinh trên Biển Đông

2.1 Phưong pháp xây dụng tập hợp bão phát sinh thống kê Monte - Carlo

Phương pháp Monte - Carlo là phương pháp dùng các thuật toán để giải các bài toán bằng cách lấy mẫu ngẫu nhiên trong một tập hợp được lặp lại nhiều lần để thu được các kết quả số. Phương pháp này thường được sử dụng để giải quyết các bài toán phức tạp liên quan đến nhiều biến số ngẫu nhiên mà không thể có lời giải bằng phương pháp giải tích và lý thuyết chính xác. Vì vậy, phương pháp Monte - Carlo đã được ứng dụng trong rất nhiều lĩnh vực khoa họa tự nhiên và xã hội. Mặc dù yêu cầu số lượng tính toán nhiều nhưng phương pháp Monte - Carlo cho kết quả tin cậy, độ ổn định cao với chu kỳ lặp lại cần quan tâm đủ lớn. Để tính toán nguy cơ nước dâng và sóng trong bão theo chu kỳ lặp nhiều năm có độ tin cậy cao, cần phải có số liệu bão (làm đầu vào cho mô hình) đủ dài trong nhiều năm. Tuy nhiên, thực tế số liệu bão có đầy đủ các thông tin cần thiết phục vụ tính toán là không nhiều và không đủ dài nên cần thiết phải xây dựng tập hợp bão phát sinh thống kê. Các đặc trưng bão trong tương lai là những biến ngẫu nhiên và không thể xác định một cách chắc chắn, do vậy lý thuyết số ngẫu nhiên áp dụng trong phương pháp Monte - Carlo được lựa chọn để xây dựng các cơn bão phát sinh thống kê là phù hợp [2].

2.2 Phưong pháp dụ báo tổ hợp và vai trò trong việc mô phỏng và dụ báo bão mạnh và siêu bão

Một hạn chế của phương pháp dự báo số là bản thân các mô hình số chưa hoàn thiện. Ví dụ như các phương pháp xấp xỉ sai phân, những quá trình vật lý quy mô nhỏ phải được tham số hóa (parameterization), các số liệu quan trắc làm đầu vào cho mô hình chưa đủ tinh để tạo ra trường ban đầu tốt nhất. Những hạn chế này sẽ gây ra sự không chắc chắn (uncertainty) trong dự báo và đã phương pháp đồng hóa tổ hợp như đã trình bày được ra đời để thay thế các kết quả duy nhất từ một mô hình (dự báo tất định) bằng các dự báo dạng xác suất tính từ tập hợp các dự báo thành phần tổ hợp nhất định (dự báo tổ hợp). 


\section{BÀI BÁO KHOA HỌC}



Hình 1. Dự báo quỹ đạo và cương độ cơn bão Rammasun tù các mô hình toàn cầu (a) ngày 17/7/2014 và quỹ đạo thực (b). Ký hiệu mô hình toàn cầu: GSM-Nhật, GFS-Mỹ, IFS-Châu Âu, GME-Đức, GEM-Canada, NAVGEM-Hải Quân Mỹ

Một minh họa cụ cho thấy vai trò của phương pháp dự báo tổ hợp và mô hình khu vực trong trường hợp cơn bão Rammasun tháng 7 năm 2014 đổ bộ vào khu vực giáp ranh Việt Nam và Trung Quốc. Trên thực tế, sau khi đi vào Biển Đông từ ngày 16 tháng 7 năm 2014, hầu hết các mô hình toàn cầu (Hình $1 \mathrm{a})$ cũng như các dự báo từ các trung tâm quốc tế (Nhật, Mỹ) đều dự báo tốt quỹ đạo của cơn bão, tuy nhiên cường độ của cơn bão chỉ nhận không vượt quá được cấp 1314 (trong hình 1, mô hình GFS của Mỹ dự báo ốp ngày 17 tháng 7 năm 2014 cường độ cao nhất so với các mô hình khác là cấp 14). Ngay cả sản phẩm tổ hợp toàn cầu Châu Âu gồm 51 thành phần (Hình $2 \mathrm{a}$ ) cũng chỉ có thành phần dự báo cao nhất cho $\mathrm{V}_{\max }$ đạt $35 \mathrm{~m} / \mathrm{s}$ (cấp 12). Tuy nhiên trong dự báo từ hệ thống tổ hợp hạn ngắn khu vực SREPS [4], với việc sử dụng mô hình khu vực độ phân giải cao hơn các mô hình toàn cầu (độ phân giải ngang $15 \mathrm{~km}$ của hệ thống SREPS so với $25-50 \mathrm{~km}$ của các mô hình toàn cầu), một số thành phần đã dự báo khả năng Vmax có thể đạt $55 \mathrm{~m} / \mathrm{s}$ ứng với cấp 16 so với thực tế cơn bão đã đạt đến cấp 15, giật cấp 16-17 khi ở gần đảo Hải Nam (Trung Quốc) (Hình 2).
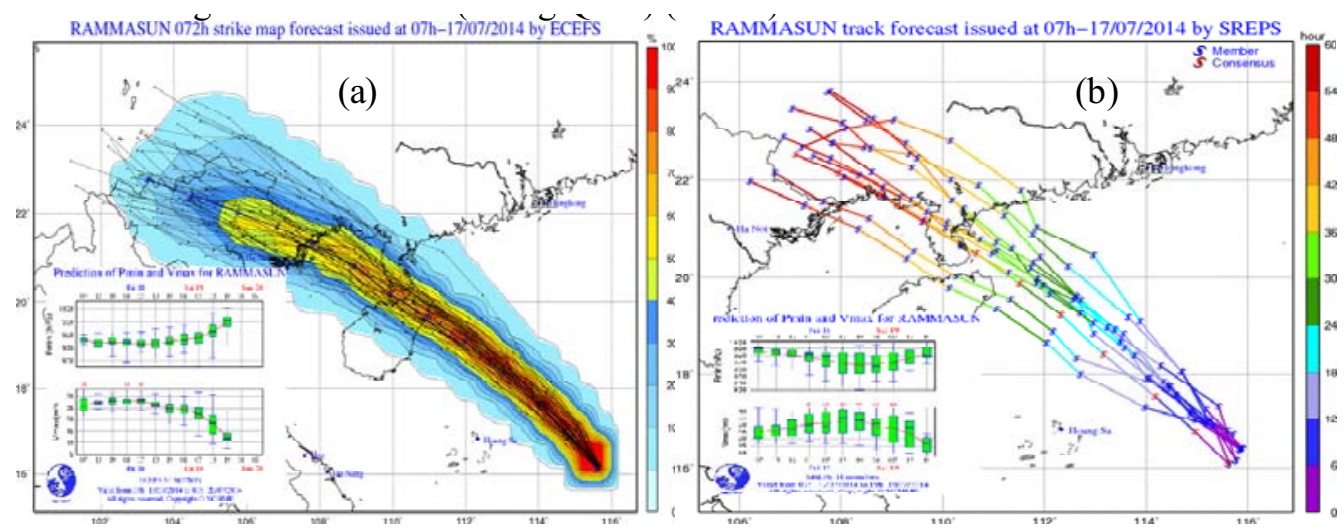

Hình 2. Dự báo quỹ đạo và cường độ con bão Rammasun tù các mô hình nghiệp vu tại Trung tâm Dư báo khi tượng thủy văn Trung ưong: hệ thống tổ hợp toàn cầu 51 thành phần của Châu Âu (a) và hệ thống SREPS tổ hợp khu vưc (b) ngày 17/7/2014

Như vậy có thể thấy được vai trò của phương pháp tổ hợp trong việc tăng cường phát hiện các trường hợp xác suất thấp có thể xảy ra cùng với khả năng tăng cường nắm bắt các hiện tượng quy mô nhỏ hơn thông qua các mô hình quy mô khu vực.

Tăng cường mô phỏng bằng mô hình khí tượng khu vực WRF-ARW. 
Với miền tính bao phủ hoàn toàn khu vực Biển Đông, hệ thống tổ hợp với 21 thành phần vật lý khác nhau dựa trên mô hình WRF-ARW đã được thử nghiệm dựa trên điều kiện biên FNL (NCEP) của hầu hết các trường hợp bão đã xảy ra trong giai đoạn 2006-2016, qua đó xây dựng bản đồ xảy ra xác suất gió mạnh nhất có thể đạt được. Trong nghiên cứu sẽ sử dụng độ phân giải mô phỏng gồm hai lưới $36 \mathrm{~km}$ và $12 \mathrm{~km}$ và kết quả cuối cùng được đánh giá dựa trên sản phẩm $12 \mathrm{~km}$. Để tăng cường cấu trúc xoáy, hệ thống được áp dụng lựa chọn cài xoáy theo phương pháp bogus thực nghiệm có sẵn trong hệ thống WRF-ARW.

\subsection{Mô phỏng khả năng xảy ra bão mạnh và} siêu bão tù̀ các sản phẩm dụ tính khí hậu

Bên cạnh các sản phẩm dự báo hạn tháng, mùa từ các mô hình toàn cầu, với ưu điểm là một bài toán biên khép kín về mặt lý thuyết và thực hành đã cho phép ứng dụng mô hình toàn cầu trong việc mô phỏng với thời gian dài hơn và tạo ra các kết quả dự tính tương lai. Nếu chỉ đơn thuần tích phân mô hình toàn cầu và giữ điều kiện biên ngoài ổn định (điều kiện bức xạ), về cơ bản các kết quả nhận được sẽ mang tính khí hậu nếu không đưa được vào các phân tích về sự biến đổi khí hậu thông qua việc thay đổi các thông số của các loại khí nhà kính - nguyên nhân chính dẫn đến sự thay đổi lực tác động bên ngoài (external forcing) đến Trái đất. Các thành phần khí quyển thay đổi dẫn đến chế độ hấp thụ bức xạ của khí quyển thay đổi, dẫn tới những hệ quả đến chế độ khí hậu của Trái đất. Quá trình xây dựng các kết quả dự tính khí hậu từ các mô hình động lực toàn cầu về cơ bản gồm 2 khâu chính là xây dựng kịch bản biến đổi các thành phần khí nhà kính và đưa vào trong quá trình tích phân mô hình. Để chi tiết hơn kết quả dự tính khí hậu từ các mô hình toàn cầu (thường có độ phân giải từ 0.5-2.5 độ kinh vĩ), có thể áp dụng phương pháp hạn quy mô động lực bằng mô hình khí hậu khu vực tương tự như cơ chế hạ quy mô động lực trong bài toán dự báo thời tiết bằng mô hình số quy mô khu vực.Kế thừa các kết quả nghiên cứu xây dựng các dự tính khí hậu cho khu vực Việt Nam và một trong những điều kiện cần để có thể áp dụng trong đánh giá các cực trị xảy ra lion quan đến bão là các sản phẩm dự tính phù hợp với bài toán đánh giá xảy ra bão trên khu vực Biển Đông Việt Nam, nghiên cứu đã lựa chọn kết quả dự tính cho kịch bản biến đổi khí hậu RCP8.5 với giải thuyết về nồng độ khí nhà kính cao, đặc trưng bởi bức xạ tác động tăng liên tục từ đầu thế kỉ 21 và đạt $~ 8.5 \mathrm{~W} / \mathrm{m}^{2}$ vào năm [1].

2.4 Mô hình tích hợp thủy triều, sóng biển và nước dâng bão

SuWAT (Surge Wave and Tide) là mô hình tích hợp thủy triều, sóng biển và nước dâng bão. Mô hình được xây dựng tại đại học Kyoto Nhật Bản [3], bao gồm 2 mô hình thành phần là: mô hình thủy triều và nước dâng dựa trên hệ phương trình nước nông phi tuyến 2 chiều có tính đến nước dâng do ứng suất bức xạ sóng và ứng suất bề mặt do sóng trong bão và mô hình SWAN tính toán sóng.

\section{Các kết quả mô phỏng}

\subsection{Tập hợp bão phát sinh bằng phương} pháp thống kê Monte-Carlo

Áp dụng phương pháp Monte-Carlo dựa vào cơ sở số liệu các tham số bão trong lịch sử hoạt động trên Biển Đông và có ảnh hưởng đến Việt Nam giai đoạn 1951 đến 2015, Trên cơ sở hàm phân phối xác suất thu được, đã xây dựng được tập hợp bão phát sinh thống kê (bão giả định) gồm trên 6213 cơn bão, trong đó có 4678 cơn bão đổ bộ vào dải ven biển Việt Nam từ Quảng Ninh đến Cà Mau. Kết quả thống kê số cơn bão theo cấp bão Bô phô tại 04 khu vực nghiên cứu là Quảng Ninh - Hà Tĩnh; Quảng Bình - Phú Yên; Khánh Hòa - Bình Thuận và Bà Rịa Vũng Tầu - Cà Mau được thể hiện trong bảng 1. 
Bảng 1. Thống kê số lương bão giả định theo các cấp bão Bô pho (số cơn/phần trăm) tại 4 khu vực tù̀ Quảng Ninh đến Cà Mau

\begin{tabular}{ccccc}
\hline \multirow{2}{*}{$\begin{array}{c}\text { Cấp bão Bô } \\
\text { pho }\end{array}$} & \multicolumn{4}{c}{ Khu vực nghiên cứu } \\
\cline { 2 - 5 } & Quảng Ninh-Hà Tĩnh & $\begin{array}{c}\text { Quảng Bình-Phú } \\
\text { Yên }\end{array}$ & $\begin{array}{c}\text { Khánh Hòa-Bình } \\
\text { Thuận }\end{array}$ & $\begin{array}{c}\text { Bà Rịa Vũng Tầu-Cà } \\
\text { Mau }\end{array}$ \\
\hline ATNĐ & $(663) / 14.17 \%$ & $(413) / 8.83 \%$ & $(139) / 2.97 \%$ & $(105) / 2.24 \%$ \\
8 & $(483) / 10.32 \%$ & $(330) / 7.05 \%$ & $(105) / 2.97 \%$ & $(72) / 1.54 \%$ \\
9 & $(505) / 10.80 \%$ & $(310) / 7.05 \%$ & $(112) / 2.39 \%$ & $(78) / 1.67 \%$ \\
10 & $(196) / 4.19 \%$ & $(122) / 2.61 \%$ & $(38) / 0.81 \%$ & $(28) / 0.60 \%$ \\
11 & $(144) / 3.08 \%$ & $(100) / 2.14 \%$ & $(24) / 0.51 \%$ & $(29) / 0.62 \%$ \\
12 & $(316) / 6.76 \%$ & $(183) / 3.91 \%$ & $(74) / 1.58 \%$ & $(44) / 0.94 \%$ \\
13 & $(18) / 0.38 \%$ & $(10) / 3.91 \%$ & $(1) / 0.02 \%$ & $(\mathbf{6}) / \mathbf{0 . 1 3 \%}$ \\
14 & $(8) / 0.17 \%$ & $(7) / 0.15 \%$ & $(2) / 0.04 \%$ & \\
15 & $(6) / 0.13 \%$ & $(2) / 0.04 \%$ & $(2) / 0.04 \%$ & \\
16 & $(\mathbf{1 )} / \mathbf{0 . 1 3} \%$ & $(1) / 0.02 \%$ & & \\
17 & & $(\mathbf{1}) / \mathbf{0 . 0 2} \%$ & & \\
Tổng & $(2340) / 50.02$ & $(1479) / 31.62$ & $(467) / 10.62$ & $(362) / 7.74 \%$ \\
\hline
\end{tabular}

\subsection{Kết quả mô phỏng nước dâng và sóng trong bão}

Do hạn chế số liệu quan trắc nước dâng và sóng trong bão nên giải pháp sử dụng số liệu tính toán từ mô hình số trị có độ tin cậy cao để thay thế là phù hợp nhất cho nghiên cứu đánh giá nước dâng và sóng trong bão tại khu vực. Kết quả tính toán cho thấy, trong giai đoạn 1951 - 2014 đã có nhiều cơn bão mạnh gây nước dâng và sóng lớn trong khu vực ven bờ cũng như một số đảo tại Việt Nam. Một số cơn bão mạnh gây nước dâng và sóng lớn phải kể tới: Tại ven biển Bắc Bộ có bão DAN (1989) đổ bộ vào Hà Tĩnh, bão Becky (1990) đổ bộ vào Nghệ An, tại ven biển Trung Bộ có bão Harriet (1971) đổ bộ vào Quảng Trị, bão Xangsane (2006) đổ bộ vào Đà Nẵng, ven biển Nam Bộ có bão Linda (1997) quét qua bán đảo Cà Mau. Ngoài ra, nhiều cơn bão mạnh không gây nước dâng lớn tại vùng ven bờ nhưng đã gây sóng lớn cho khu vực biển ngoài khơi cũng như tại đảo Hoàng $\mathrm{Sa}$ và Trường $\mathrm{Sa}$ của Việt Nam, như Chanchu (2006), Haiyan (2013).

Trên hình 3a-b là phân bố nước dâng bão lớn nhất trong bão DAN (1989)và Harriet (1971), đây là 2 cơn bão gây nước dâng kỷ lục. Trong đó, bão Harriet với cường độ lúc cập bờ lên tới cấp 14 đã gây nước dâng lơn trên một phạm vi rất rộng, vùng có độ lớn nước dâng lớn hơn $2 \mathrm{~m}$ trải dài từ Cửa Giang tới phía Nam của Huế. Trường độ cao sóng lớn nhất trong bão $\mathrm{DAN}$ và Harriet được thể hiện trên hình $5 \mathrm{a}-\mathrm{b}$ cho thấy hai cơn bão vừa có cường độ mạnh lại di chuyển trong vùng biển thoáng nên đã tạo lên độ cao sóng ngoài khơi lên tới $15 \mathrm{~m}$ (bão Harriet) và $12 \mathrm{~m}$ (bão $\mathrm{DAN})$. Ở khu vực sát bờ, sóng trong bão Harriet cũng lên tới $8 \mathrm{~m}$, và $6 \mathrm{~m}$ trong bão DAN.
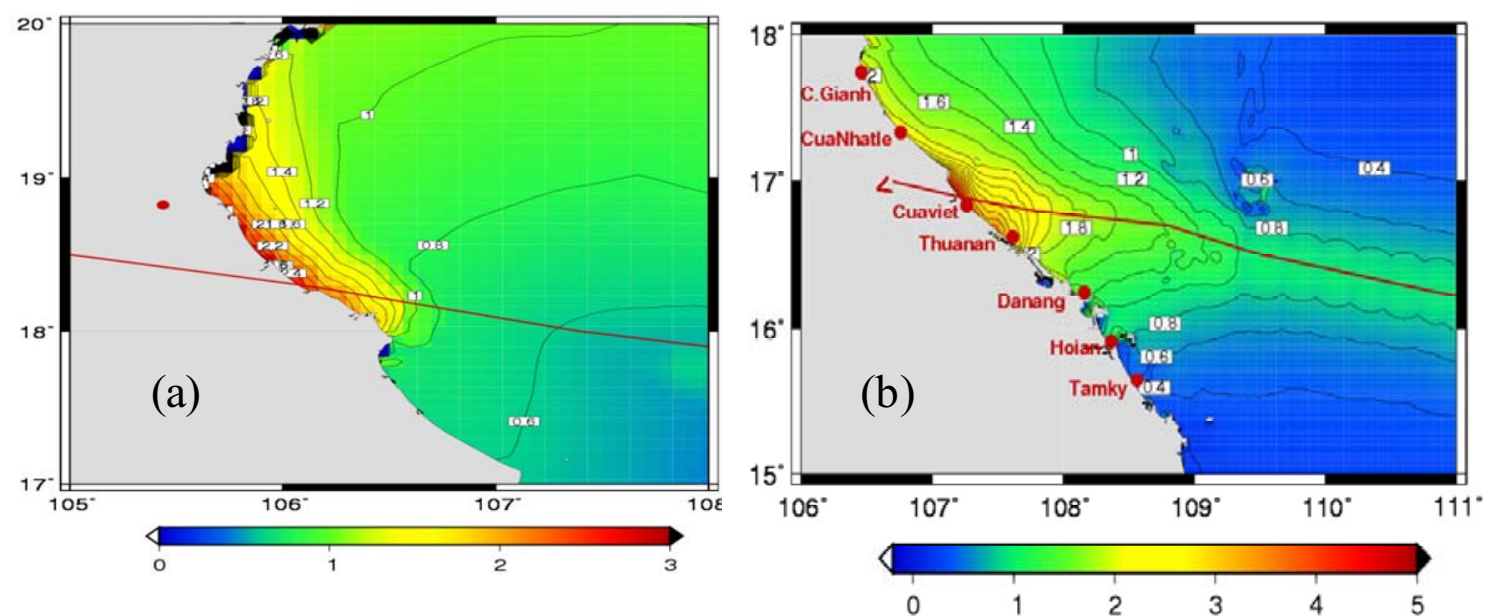

Hình 3. Phân bố độ cao nước dâng lơn nhất trong bão DAN,1989 (a) và Harriet, 1971(b) 


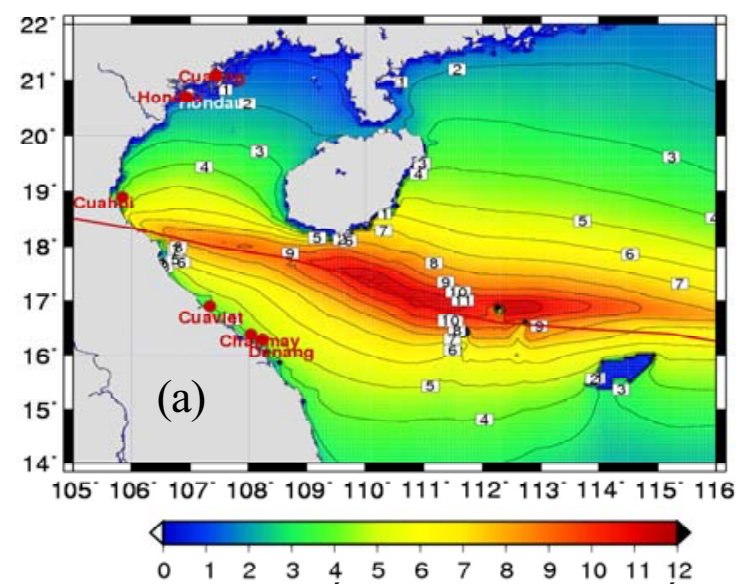

Hình 4. Phân bố độ cao sóng lón nhất trong

Trên Hình 5 thể hiện phân bố nước dâng bão lớn nhất tại giải ven biển và hai khu vực đảo lớn của Việt Nam trong giai đoạn 1951-2014, tất cả được phân theo 8 vùng, Quảng Ninh-Thanh Hóa (a), Nghệ An - Quảng Bình (b), Quảng Trị Quảng Ngãi (c), Bình Định - Ninh Thuận (d), và Bình Thuận - Cà Mau (e), Cà Mau - Kiên Giang (f), Quần Đảo Hoàng $\mathrm{Sa}(\mathrm{g})$ và Quần Đảo Trường $\mathrm{Sa}(\mathrm{h})$. Theo đó, tại ven biển từ Quảng Ninh tới Thanh Hóa nước dâng bão lớn nhất lớn nhất tới 3,0m đã xuất hiện tại một số khu vực như ven biển Quảng Ninh, Hải Phòng, Thái Bình và Nam Định. Phần lớn các khu vực trong dải ven biển này đã từng xuất hiện nước dâng bão lớn tới 2,0m. Một số cơn bão gây nước dâng lớn tại khu vực này như Frankie (1996), Damrey (2005), Kalmaegy (2014). Ven biển từ Nghệ An tới Quảng Bình là nơi đã ghi nhận nhiều cơn bão gây nước dâng lớn trên dải ven biển Việt Nam. Một số cơn bão gây nước dâng lớn tại khu vực này như DAN (1989) đổ bộ vào Hà Tĩnh, Becky (1990) đổ bộ vào Nghệ An, Harriet (1971) đổ bộ vào Quảng Trị. Trong đó bão Harriet mặc dù đổ bộ vào Quảng Trị nhưng cũng đã gây nước dâng lớn hơn 2,0m cho một số khu vực ở Nam Quảng Bình. Tại khu vực này, nước dâng bão lớn nhất lên tới 4,0m tập chung tại một số vị trí ở phía nam khu vực. Toàn bộ dải ven biển trong khu vực này đều ghi nhận có nước dâng bão lớn hơn $2,5 \mathrm{~m}$ và dải đất liền ở phía Nam khu vực có nước dâng bão lớn hơn ở phía Bắc. Trong dải ven biển từ Quảng Trị tới Quảng Ngãi, nước dâng cao

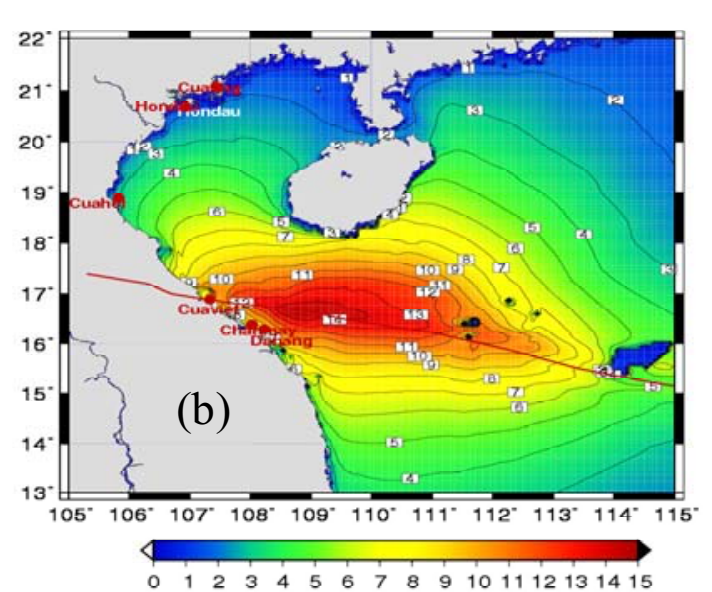

ng bão DAN,1989 (a) và Harriet, 1971 (b)

nhất có xu thế chung là giảm dần từ bắc vào nam theo xu thể giảm về tần suất và cường độ bão. Tại phía bắc khu vực, đây là nơi có nhiều cơn bão mạnh đổ bộ nên đã gây nước dâng lớn. Các cơn bão như Harriet (1971), Cecil (1985), Betty (8/1987), Xangsane (9/2006), Ketsana (9/2009) đã gây nước dâng lớn trên 2,0m tại khu vực quanh vị trí bão đổ bộ, trong đó bão Harriet (7/1971) đã gây nước dâng lớn hơn 4m tại Quảng Trị. Trong khu vực ven biển từ Quảng Ngãi tới Ninh Thuận nước dâng bão lớn nhất cũng có xu thế giảm dần từ bắc vào nam. Những nơi có nước dâng tới 1,0m tập chung chủ yếu ở phía bắc khu vực. Nước dâng bão tại dải ven biển này thấp do bởi đây là khu vực có ít cơn bão mạnh ảnh hưởng, cũng đã có bão mạnh tại khu vực này nhưng hướng di chuyển không thuận tiên cho gây nước dâng (bão Durian, 2006 di chuyển xiên với đường bờ). Ngoài ra, đây là khu vực biển có độ sâu lớn và dốc, đây là nhân tố làm hạn chế độ cao nước dâng bão. Tại dải ven biển từ Bình Thuận-Cà Mau, đây là khu vực rất ít bão ảnh hưởng, tuy nhiên gần đây cũng đã ghi nhận nước dâng bão lên tới $1,5 \mathrm{~m}$ trong bão Landa (1997). Khu vực ven biển từ Cà Mau tới Kiên Giang có nước dâng bão nhỏ, do phần lớn các cơn bão ảnh hưởng tới khu vực này đều qua đi qua phần đất liền của Nam Bộ do vậy cường độ đã giảm đáng kể. Ngoài ra, với hướng bão chủ yếu theo hướng tây cũng là nhân tố không thuận lợi gây nước dâng bão trong khu vực. Đối với khu vực đảo ngoài khơi, do có vùng đất che chắn 
không lớn nên nước dâng do bão tại các khu vực này chủ yếu là do sự giảm khí áp tại trong bão gây nên và nước dâng do ứng suất gió đóng góp không lớn. Khu vực quần đảo Hoàng Sa là nơi có nhiều cơn bão mạnh đi qua, bao gồm cả các cơn bão không đổ bộ trực tiếp vào đất liền Việt Nam hoặc có vào nhưng cường độ đã giảm mạnh
(Chanthu, 2006, Hayan, 2013) nên đã gây nước dâng lớn nhất tới $1,5 \mathrm{~m}$, tập chung chủ yếu ở các cụm đảo ở phía Đông của Quần đảo Hoàng Sa. Với quần đảo Trường $\mathrm{Sa}$, nước dâng bão nhỏ hơn và phần nước dâng lớn ở khu vực phía bắc cũng chỉ tới $0,5 \mathrm{~m}$.
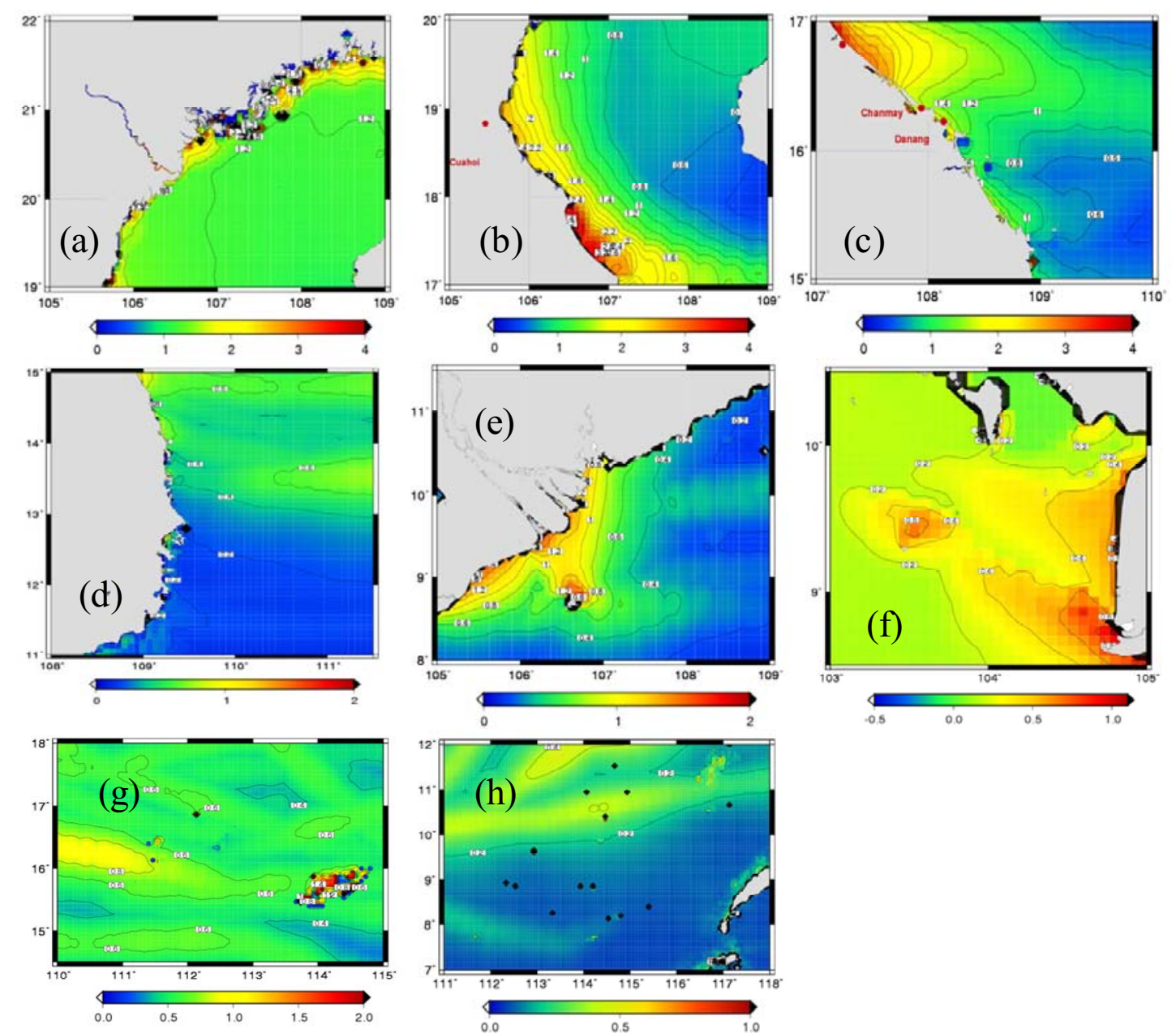

Hình 5. Phân bố nước dâng bão lớn nhất tại các khu vục trong giai đoạn 1951-2014: (a) Quảng

Ninh - Thanh Hóa; (b) Nghệ An - Quảng Bình; (c) Quảng Trị - Quảng Ngãi; (d) Bình Định Ninh Thuận; (e) Bình Thuận - Cà Mau; (f) Cà Mau - Kiên Giang; (g) Quần đảo Hoàng Sa; (h) Quần đảo Truò̀ng $\mathrm{Sa}$

\subsection{Kết quả mô phỏng gió mạnh trong bão bằng mô hình khí tựng}

3.3.1 Kết quả mô phỏng xác suất gió mạn tì hệ thống tổ hợp toàn cầu

Trong những năm vừa qua các trung tâm quốc tế lớn trên thế giới như Anh, Mỹ, Châu Âu, Trung Quốc, Nhật bản... đã thống nhất chia sẻ các sản phẩm dự báo tổ hợp toàn cầu về bão để tái xử lý thành một sản phẩm dự báo siêu tổ hợp toàn cầu (grand global ensemble). Từ năm 2011, WMO đã lựa chọn Tổng cục KTTV đóng vai trò như là một trung tâm dự báo khu vực trong dự án SWFDP-SeA. Thông qua Cục dự báo khí tượng Nhật Bản - JMA [5], nghiên cứu đã được cung cấp chi tiết sản phẩm số về quỹ đạo và cường độ dự báo của hệ siêu tổ hợp này trên khu vực Biển Đông từ năm 2006-2016. Việc xây dựng các bản đồ xuất hiện bão mạnh và siêu bão cũng sẽ đóng 
góp các thông tin để xác định phân vùng cuối cùng cho các nơi có khả năng xuất hiện bão mạnh và siêu bão trên Biển Đông và ảnh hưởng đến Việt Nam. Minh họa dự báo siêu tổ hợp cho cơn bão Haiyan năm 2013 và khai thác sản phẩm này trên cổng chia sẽ cho dự án SWFDP-SeA của Nhật bản (Hình 6).

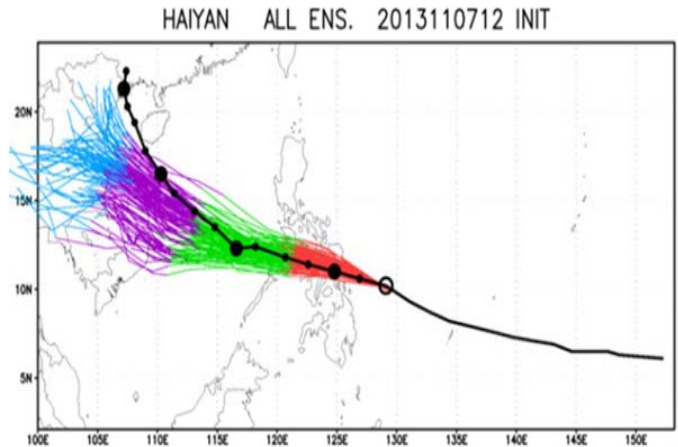

(a)

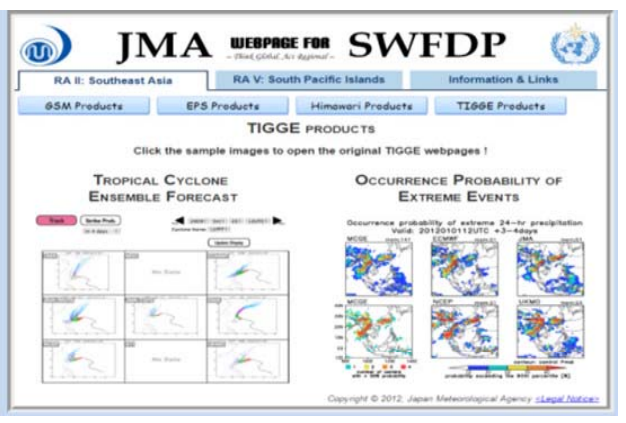

(b)

Hình 6. Dự báo cơn bão Haiyan năm 2013 tù hệ siêu tổ hợp toàn cầu (a) và được chia sẻ bởi JMA thông qua dụ án hỗ trợ khu vục SWFDP-SeA (b)
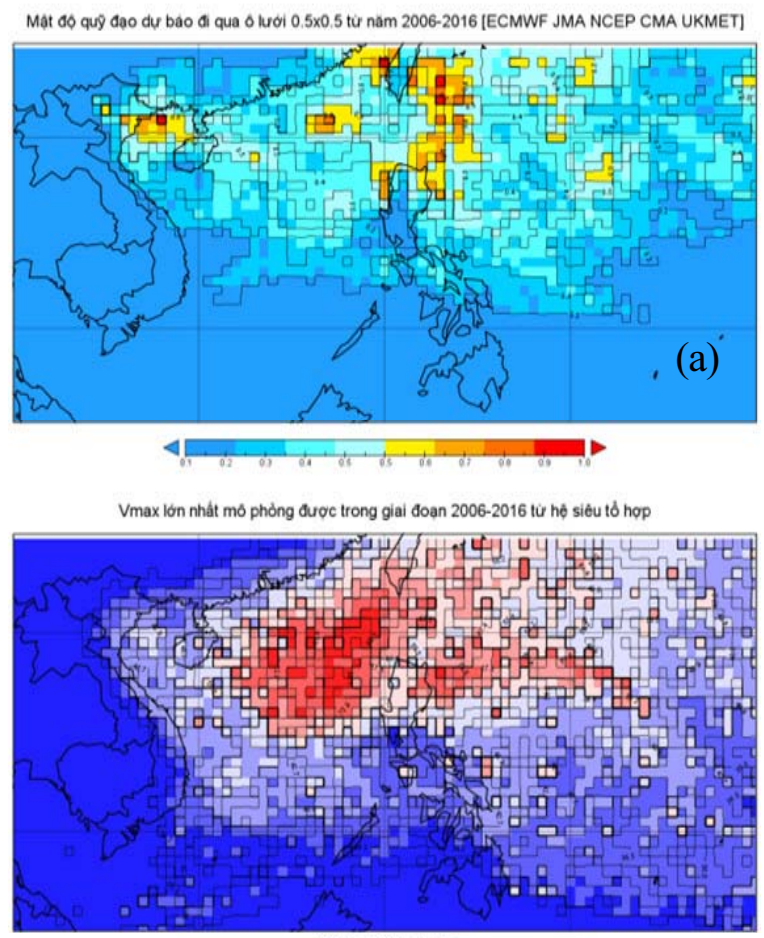

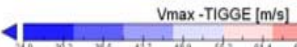

(b)

Hình 7. (a) Xác suất dư báo đi qua tùng ô lưới tù sản phẩm tổ hợp toàn cầu. Đơn vị 1 ứng với 100\% khả năng sẽ xảy ra; (b) Tốc độ gió cực đại tại tùng ô lưới

Để xây dựng bản đồ khả năng xảy ra, toàn bộ miền tính sẽ được chia thành lưới ô vuông có kích thước $50 \mathrm{~km} \times 50 \mathrm{~km}$ và ứng với tập các quỹ đạo bão đi qua từng ô lưới sẽ xác định giá trị cực đại của cường độ bão đạt được từ tập dự báo của hệ thống tổ hợp toàn cầu. Đánh giá chung sự ổn định của sản phẩm dự báo, chúng nghiên cứu chỉ lựa chọn 5 dự báo từ Châu Âu (ECMWF, 51 thành phần), Nhật (JMA, 51 thành phần), Mỹ (NCEP, 21 thành phần), Trung Quốc (CMA, 15 thành phần) và Anh (UKMET, 24 thành phần) từ năm 2006 - 2016. Trong hình 7 là xác suất dự báo khả năng đi qua (a) và cường độ $(\mathrm{b})$ đạt được cực đại trên từng ô lưới. Úng với một ốp dự báo 


\section{BÀI BÁO KHOA HỌC}

có 172 thành phần dự báo. Từ hình 8 (a) cho thấy khu vực dễ xảy ra cấp siêu tập trung tại vùng Bắc và giữa $\mathrm{Biển} \mathrm{Đông.} \mathrm{Một} \mathrm{số} \mathrm{trường} \mathrm{hợp} \mathrm{đạt} \mathrm{trên}$ cấp 14 có thể xảy ra trên vùng ven biển Đông Bắc và Trung Trung Bộ. Dưới vĩ tuyến $9^{\circ}$ Bắc rất khó có khả năng mô phỏng được gió bão mạnh trên cấp 12-13. Vùng biển Nam Bộ hầu như chỉ ảnh hưởng bởi bão dưới cấp 10-11. Ngoài ra cũng cho thấy ảnh hưởng của bão mạnh cấp 12-13 trên đất liền có thể xảy ra từ Đông Bắc Bộ kéo dài đến Nam Trung Bộ. Mức độ ảnh hưởng sâu vào đất liền nhất của bão trên cấp 12 xảy ra tại khu vực từ Hải Phòng đến hết Thừa Thiên Huế (lấn sâu có thể đạt $150 \mathrm{~km}$ tại khu vực

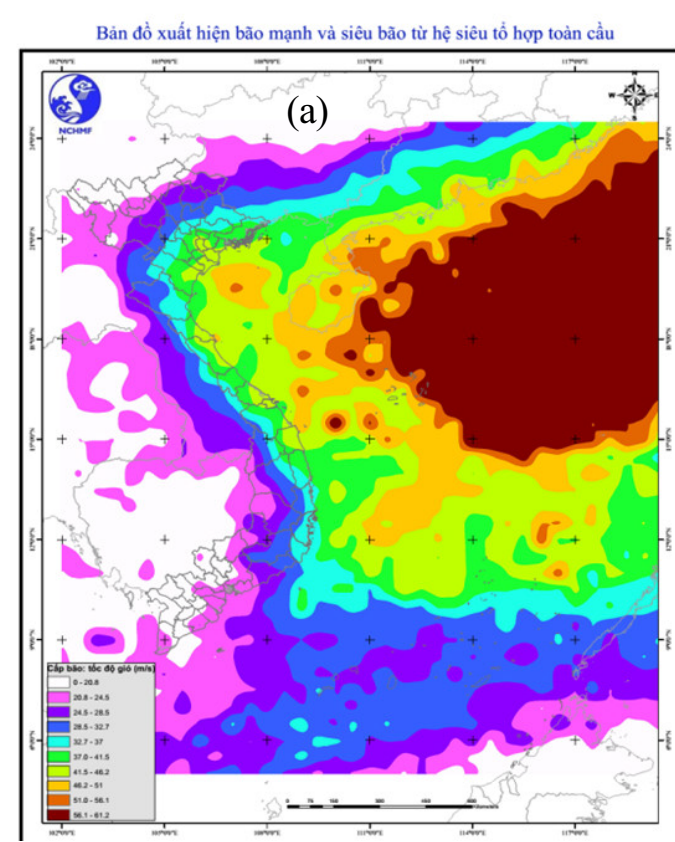

Đồng bằng Bắc Bộ).

3.3.2 Kết quả mô phỏng xác suất gió mạn tùt hệ thống tổ hợp khu vục

Trong hình 8 (b) là kết quả tổng hợp khả năng xảy ra bão mạnh nhất có thể từ hệ thống tổ hợp khu vực (tương tự cách xác định giống với hệ thống dự báo tổ hợp mục 3.3.1 nhưng sử dụng trên lưới mô hình khu vực). Ta thấy rằng khả năng xảy ra cấp 15 trở lên xảy ra ở hầu hết trên khu vực bắc Biển Đông, giữa Biển Đông và ven biển Trung Trung Bộ. Đối với cấp bão từ 14 trở lên có thể xảy ra tại các vùng biển từ Đông Bắc kéo dài đến Nam Trung Bộ.

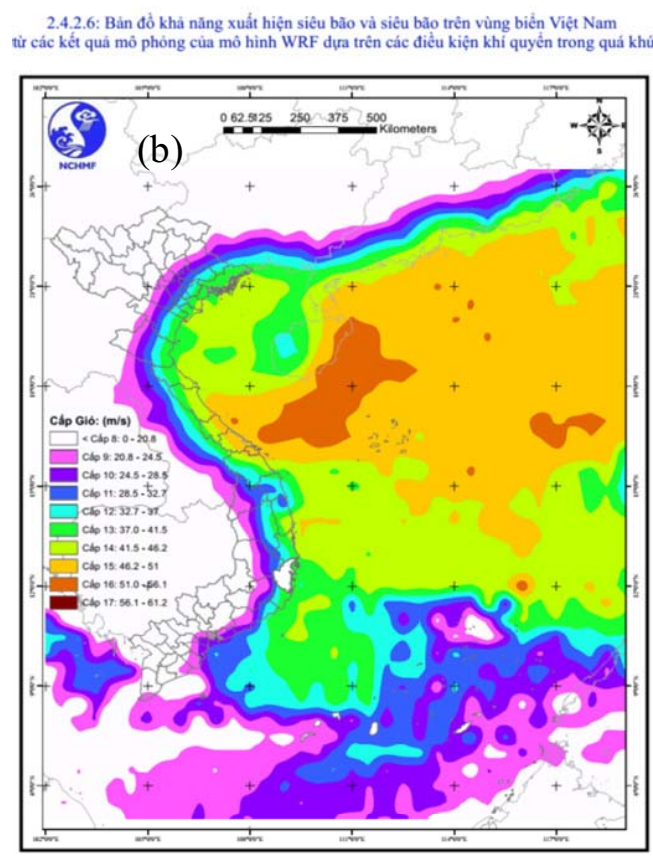

Hình 8. Bản đồ cấp bão cực đại có thể mô phỏng được trên tùng ô lưới tù siêu tổ hợp toàn cầu (a) và tù hệ thống tổ hợp khu vưc (b)

Khác so với các sản phẩm dự tính khí hậu khu vực hay siêu tổ hợp toàn cầu, khu vực biển Nam Trung Bộ và xuống tới vĩ độ $9^{\circ}$ Bắc vẫn có thể đạt cấp 13 . Ở vĩ độ từ 6-8 Bắc vẫn mô phỏng được một số trường hợp đạt cấp 12 (nam Biển Đông). Về mức độ ảnh hưởng trên đất liền, độ lấn sâu của cấp bão từ cấp 12-13 trở lên cũng kéo dài từ Bắc Bộ đến Trung Bộ tuy nhiên chỉ khoảng $40-50 \mathrm{~km}$. Khu vực tập trung siêu bão (cấp 16) chủ yếu nằm ở phía Đông và Nam đảo Hải Nam và ảnh hưởng trực tiếp đến khu vực Trung Trung Bộ. Ngoài những cơn bão có cường độ mạnh di chuyển dọc theo bờ biển Trung Bộ (điển hình như cơn bão Sơn Tinh năm 2012 và Haiyan năm 2013) thì những cơn bão di chuyển ngang, nhanh và có cường độ mạnh sẽ có xác suất rất cao giữ được cấp rất mạnh hoặc siêu bão khi đổ bộ vào khu vực miền Trung.

\subsubsection{Kết quả mô phỏng xác suất gió mạh tì̀} dụ tính khí hậu khu vục

Với mục tiêu kế thừa các sản phẩm dự tính khí hậu để dò tìm các dạng xoáy bão mạnh hoạt động trên khu vực Biển Đông, nghiên cứu đã đánh giá khả năng phát sinh bão mạnh và siêu 
bão từ tập dự tính khí hậu giai đoạn 2020-2100. Một số kết quả về tỉ lệ bão hoạt động trung bình các thàng $5,6,7$ và 8 từ sản phẩm dự tính này được minh họa trong hình 9 (a). Hình này cho thấy bão hoạt động nhiều nhất ở khu vực bắc và giữa Biển Đông trong khi khả năng xuất hiện bão với cường độ gió bề mặt mạnh trên $40 \mathrm{~m} / \mathrm{s}$ ứng với cấp 13 hầu như không xảy ra. Về nguyên nhân dự tính cường độ bão thấp có thể xuất phát từ hai nguyên nhân chính bao gồm việc mô hình mới chỉ dừng ở độ phân giải $20 \mathrm{~km}$ và mô phỏng ở dạng tất định nên phần nào sẽ hạn chế khả năng mô phỏng được các trường hợp phát sinh bão rất mạnh và siêu bão. Tương tự trong việc xây dựng bản đồ khả năng xảy ra gió mạnh cực đại trên Biển Đông và lãnh thổ Việt Nam, toàn bộ dự báo từ kết quả dự tính khí hậu giai đoạn 2015-2100 được minh họa trong hình 9 (b).
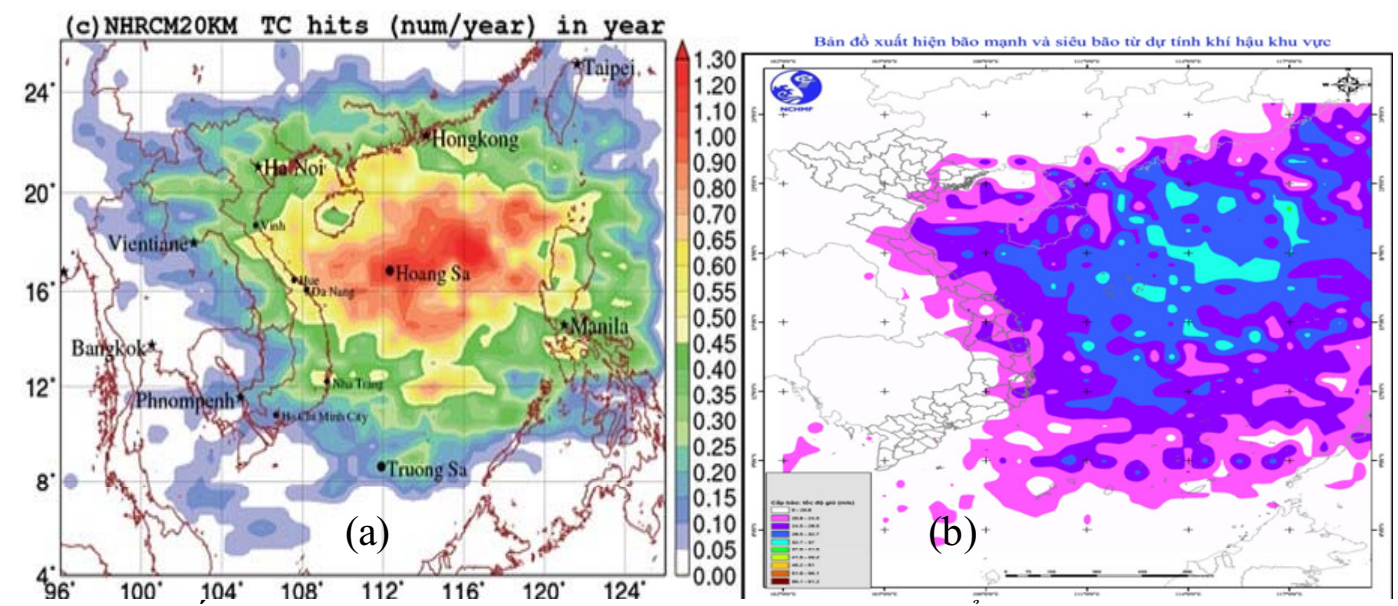

Hình 9. Số con bão có khả năng xảy ra trong năm tù sản phẩm dụ tính khí hậu khu vực và tần xuất suất hiện các cường độ bão dự tính được (a) và bản đồ cấp bão cực đại có thể mô phỏng được trên tùng ô lưới (b)

Ta thấy rằng đối với cấp bão rất mạnh trên cấp 13 chỉ dự tính xảy ra trên vùng Bắc Biển Đông. Khu vực vùng biển ven Đông Bắc và Trung Bộ có khả năng xảy ra gió bão mạnh khoảng cấp 12 . Như đã phân tích, việc chỉ phát hiện gió mạnh đạt tối đa cấp 12-13 của sản phẩm dự tính khí hậu khu vực xuất phát từ độ phân giải $20 \mathrm{~km}$ của sản phẩm và đây là sản phẩm dự báo tất định nên những xác suất xảy ra các cực trị trong từng ốp dự tính sẽ giảm đi rất nhiều. Ngoài ra cũng nhận thấy vùng Bắc Biển Đông và giữa Biển Đông vẫn là nơi có khả năng xảy ra bão trên cấp 12 nhiều nhất. Về cường độ bão mạnh ảnh hưởng sâu vào đất liền từ dự tính khí hậu khu vực cho thấy khu vực miền Trung có khả năng chịu gió mạnh cấp 9-10 cao nhất.

\section{Kết luận}

Dựa trên các sản phẩm dự báo thống kê-động lực từ mô hình hải văn và khí tượng cho thấy đối với vấn đề nước dâng do bão (trên cơ sở số liệu bão phát sinh thống kê trong 1000 năm), những khu vực có nước dâng bão lớn là ven biển Quảng Ninh - Hải Phòng (4.5m), Thanh Hóa - Nghệ An (4.0m), Quảng Trị (5.0m). Dải ven biển Nam Bộ cũng có nguy cơ nước dâng bão tới 2,5m. Tại ven biển miền Trung từ Quảng Trị-Ninh Thuận, độ cao sóng ngoài xa bờ có thể lên tới $15 \mathrm{~m}$, vùng sát bờ $7-8 \mathrm{~m}$. Kết quả tính nước dâng và sóng trong bão giai đoạn 1951-2015 tại dải ven biển Việt Nam và 2 quần đảo Hoàng Sa và Trường $\mathrm{Sa}$ cho thấy, nước dâng bão có độ lớn trên $2,0 \mathrm{~m}$ chủ yếu tập trung ở ven biển từ Quảng Ninh đến Quảng Bình, khu vực có nước dâng trên 3,0 m đã xuất hiện tại ven biển tỉnh Nghệ An, Quảng Trị và Huế, đặc biệt có một lần nước dâng bão lên tới 4,1m tại Quảng Trị trong bão Harriet (7/1971) với sức gió cấp 14 khi đổ bộ.

Liên quan đến cường độ bão từ phương pháp Monte-Carlon cho thấy tính toán, Vùng I: Quảng Ninh - Hà Tĩnh là vùng có số cơn bão đổ bộ và ảnh hưởng nhiều nhất, vùng chịu ảnh hưởng của bão sớm hơn các vùng khác với thời kỳ nhiều 


\section{BÀI BÁO KHOA HỌC}

bão nhất là 3 tháng giữa mùa hè $(6,7,8)$. Cường độ bão đã ghi nhận được là cấp 14, tính toán bằng phương pháp tổ hợp khu vực này bão có thể mạnh tới cấp 14-15, trong khi bằng phương pháp Monter-Carlo trong tương lai bão có thể mạnh tới cấp 16. Đối với khu vực từ Quảng Ninh - Hà Tĩnh cường độ bão mạnh nhất trong tương lai có thể lên tới cấp 15-16, giật trên cấp 17. Đối với Vùng II: Quảng Bình (nam Đèo Ngang) Phú Yên (phía Bắc đèo Cả) sẽ có tần số bão hàng năm 1,0 - 1,5 cơn, mùa bão lùi về nửa cuối mùa hè, tập trung vào các tháng $8,9,10$. Cường độ bão đã ghi nhận được là cấp 13. Đối với Vùng III: Khánh Hòa - Bình Thuận sẽ là vùng có tần số bão hàng năm ít hơn so với vùng 3 , mùa bão lùi sâu về đầu mùa đông, khoảng tháng 11, 12. Cường độ bão đã ghi nhận được là cấp 13 . Vùng IV: Ninh Thuận - Cà Mau là vùng có tần số bão trung bình năm ít nhất trong số các vùng, mùa bão lệch hẳn về mùa đông tháng 11,12 . Cường độ bão đã ghi nhận được là cấp 10 .
Dự báo tổ hợp quy mô toàn cầu cho thấy khu vực xảy ra siêu bão nằm tại khu vực bắc Biển Đông và giữa Biển Đông. Các cấp 14-15 có thể xảy ra trên vùng biển Bắc Bộ và Trung Bộ. Không mô phỏng được gió mạnh trên cấp 12 ở dưới vĩ tuyến $10^{\circ}$ Bắc. Ngoài ra, dự báo tổ hợp quy mô khu vực cho phép tăng khả năng mô phỏng được các trường hợp xảy ra cực trị gió mạnh. Với thử nghiệm sử dụng điều kiện biên tái phân tích trong quá khứ cho thấy khả năng xảy ra bão mạnh từ cấp 15 trở lên tập trung chủ yếu tạp khu vực bắc Biển Đông, giữa Biển Đông và ven biển Trung Trung Bộ. Khu vực vùng biển Bắc Bộ và Bắc Trung Bộ xảy ra cấp 14 trở lên. Dưới vĩ tuyến $10^{\circ}$ Bắc không mô phỏng được gió mạnh trên cấp 13. Bên cạnh đo, dự tính khí hậu kịch bản phát thải lớn (RCP8.5) giai đoạn 20152100 cho thấy xác suất thấp của việc bão đạt cường độ trên $40 \mathrm{~m} / \mathrm{s}$ (cuối cấp 13 ) và khu vực xảy ra bão mạnh nhất nằm ở khu vực Bắc Biển Đông.

Lời cảm ơn: Nội dung của nghiên cứu được thực hiện trong khuôn khổ đề tài cấp Bộ Tài nguyên và Môi truòng "Nghiên cứu khả năng xuất hiện bão mạnh, siêu bão trên các khu vục khác nhau của Việt Nam và hệ quả mura, gió mạnh, nuớc biển dâng phục vu phương án úng phó”, mã số 2015.05.07 và được tài trợ bởi Sở Khoa học và Công nghệ tỉnh Thái Bình trong dề tài "Nghiên cứu xây dụng mô hình dư báo nước dâng, sóng lớn do bão kết hợp với triều cuờng gây ngập lụt ven biển tỉnh Thái Bình", mã số TB-CT/CN03/19. Tác giả xin chân thành cảm ơn.

\section{Tài liệu tham khảo}

1. IPCC (2012), The Innovative Program of Climate Change Projection for the 21st Century https:/www.ipcc.ch/site/assets/uploads/2018/03/WG1AR5_SummaryVolume_FINAL.pdf

2. Đinh Văn Mạnh và cộng sự (2011), Phát triển và hoàn thiện mô hình dụ bão sóng bão, nước dâng do bão, thủy triều cho dải ven biển Việt Nam. Báo cáo tổng kết nghiên cứu, Viện Cơ học, Hà nội.

3. Thai, Tran Thuy, Nguyen, Vu Hai, Dang, Kim, Sooyoul Hole, Lars. (2017), Impact of the interaction of surge, wave and tide on a storm surge on the north coast of Vietnam. Procedia IUTAM, 25, 82-91. Doi:10.1016/j.piutam.2017.09.013.

4. Võ Văn Hòa, Bùi Minh Tăng, Phan Văn Tân (2013), Nghiên cứu nâng cao chất lượng dự báo trung bình tổ hợp và xác suất của hệ thống SREPS bằng cách hiệu chỉnh hàm phân bố dụ báo. Tạp chí KTTV, tháng 2/2014.

5. Yamaguchi, M., Nakazawa, T., Hoshino, S., (2012), On the relative benefits of a multi-centre grand ensemble for tropical cyclone track prediction in the western North Pacific. Quarterly Journal of the Royal Meteorological Society, 138, 2019-2029. 


\title{
THE USE OF INFORMATION FROM DYNAMICAL ATMOSPHERE AND MARINE MODELING SYSTEMS TO DETERMINE THE PROBABILITIES OF EXTREME FEATURES OF TROPICAL CYCLONE INTENSITY AND STORM SURGE IN VIETNAM'S COASTAL AREAS
}

\author{
Tran Hong Thai ${ }^{1}$, Mai Van Khiem ${ }^{1}$, Nguyen Van Huong ${ }^{1}$, Nguyen Ba Thuy ${ }^{1}$, Du Duc Tien ${ }^{1}$ \\ ${ }^{1}$ Viet Nam Meteorological and Hydrological Administration, No. 8 Phao Dai Lang Str., \\ Dong Da, Hanoi
}

\begin{abstract}
Typhoon Haiyan in 2013 was one of most powerful tropical cyclones ever recorded that resulted in severe damage to lives and properties in the Philippines. To avoid the similar risk for Vietnam, Prime Minister requested preparedness planning to respond to this super typhoon, especially the scientific analysis to provide the preliminary prediction for extreme typhoon intensity and storm surge that potentially affecting the coastal areas of Vietnam (Official Letter No. 3912/VPCPKTN dated May 30, 2014 of the Government Office on the implementation of mission to proactively respond to super typhoon). The use of physical simulation and ensemble predictions in particular allows us to predict the likelihood of extreme typhoon intensity and strom surge in addition to the observed extreme in the coastal areas of Vietnam.
\end{abstract}

Keywords: Storm surge extreme, tropical cyclone intensity extreme, Vietnam coastal. 